\title{
OCCLUSAL TRAUMA OF IMPLANT-SUPPORTED METAL-CERAMIC CROWN: A CASE REPORT
}

D0l:10.36740/WLek202102136

\author{
Olena 0. Fastovets, Roman A. Kotelevskyi, Yurii S. Huriev, Serhii S. Kobyliak \\ STATE INSTITUTION “DNIPROPETROVSK MEDICAL ACADEMY OF THE MINISTRY OF HEALTH OF UKRAINE”, DNIPRO, UKRAINE
}

\begin{abstract}
In this article there is a clinical case of occlusion trauma of implant-supported metal-ceramic crown for prosthetics of central incisor. Its uniqueness is the possibility to save dental implant after acute occlusion impact, which was strong enough to break ceramic facing of fixed denture, but not able to destroy bone and implant components. The occlusion force located at the incisal edge of the crown induced a reverse torque to the implant and did not result in its failure or bone resorption. In a year after repeated fixed prosthetics, the results of clinical examination proved absence of any problem with osseointegration. Literature analysis lets us to suggest, that the phenomenon was caused by protective action of cortical bone around of dental implant. Besides, in the case of natural tooth, the bone is suddenly compressed against the conical root; it transfers occlusal breaking to the supporting periodontal ligament. A dental implant has no periodontal ligament but can have a rough surface that may preclude implant failure.
\end{abstract}

KEY WORDS: dental implant, fixed denture, occlusal trauma

Wiad Lek. 2021;74(2):371-374

\section{INTRODUCTION}

Initial stability of dental implant is an important factor of prosthetic success. According literature analysis, immediately loaded implant has micro-motion of less than $150 \mathrm{pm}$. So, it is still osseointegrate; excessive micro-motion causes fibrous encapsulation [1]. However, the more significant trauma for a dental implant is an occlusion load. But the process of osseointegration depends not only on character of occlusion but on density of bone tissue, surface texture, diameter and length of the implant [2-4].

The occlusal trauma damages osteocytes and cellular structures that are in close proximity to implant surface and create a space between the implant and bone for epithelial down-growth. Occlusion forces in the lateral parts of dentitions are about 120 and $150 \mathrm{~N}$. Occlusal load of less than $200 \mathrm{pm}$ shows no significant increase of implant load level. Thus, these occlusal forces may not cause failure of integrated implants if they do not induce a micro-movement of more than $150 \mathrm{pm}$ [5]. The most dangerous occlusion forces are chronic, severe, and variable in magnitude, with different eccentric direction and frequency [6-7]. In turn, short implants can be used for anchorage for the small, unidirectional and constant forces for orthodontic tooth movement [8].

The interaction of bone and implant interfaces under an occlusion force is unknown. A study in rabbit femurs showed that the torque removal force of implants ranged from 27 to $59 \mathrm{~N}$ at 3-month post-insertion [9]. Titanium oxide layer thickness, micropore configurations and its crystal structures apparently affect bone tissue response. $600-1000 \mathrm{~nm}$ of oxide layers demonstrated significantly stronger bone responses in evaluation of removal torque than implants with an oxide layer less than $200 \mathrm{~nm}$ [10].
It has been suggested that a placement torque force of greater that $42 \mathrm{~N} / \mathrm{cm}$ allows a newly installed implant to be immediately subjected to non-functional load. That is, a newly placed single implant can be fitted immediately with a provisional crown but so as to be out of the path of movement of the opposing teeth [11].

In these cases, the occlusal forces of the opposing dentition are not in direct contact with the new crown and implant complex. The forces to bear are usually those of the soft tissues of tongue and mucosa and compressed food boluses from mastication. The bone around the newly placed implant is probably able to resist these lesser forces and would not move the newly placed implant more than $150 \mathrm{pm}$ in the required rigid bone that encases it [12].

The immediate placement and functional (occlusion) load is possible with cross-arch stabilization, but the survival rate is $85 \%$. Implant immobilization brought with the arch form of denture distributes occlusal load. This arch form distribution and multiplicity of implants probably prevents any implant movement beyond $150 \mathrm{pm}$ [13].

The dental implants located in the anterior part of mandible can be placed in immediate true function and provide immediate retention for an overdenture [14]. In maxillary overdentures with four to six implants, the forces of occlusion can loosen component screws, but apparently do not readily cause implant loss in the short term [15].

Coming from all the above, we considered it worthwhile to consider to the following case from our practice. It seems to be interesting because of abnormal occlusion load (trauma) in contrast to the literature data on physiological occlusion. 


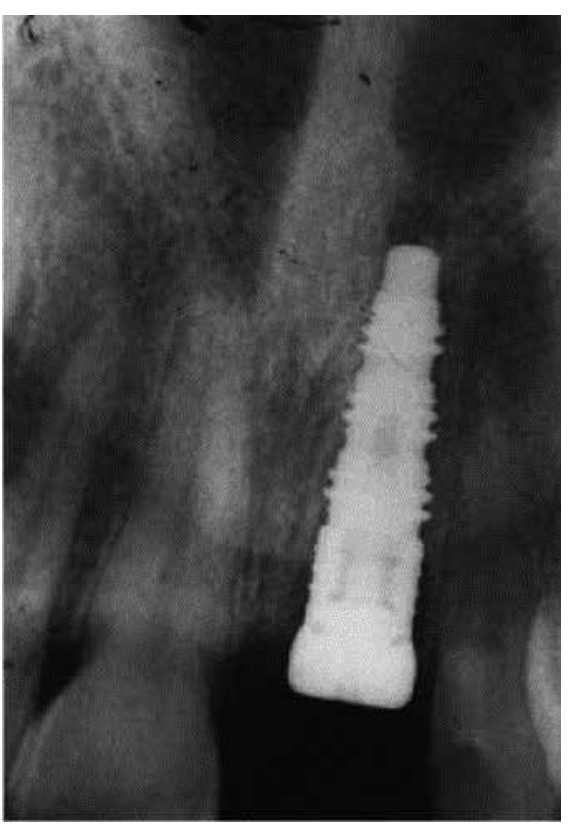

Fig. 1. Post-operative radiography

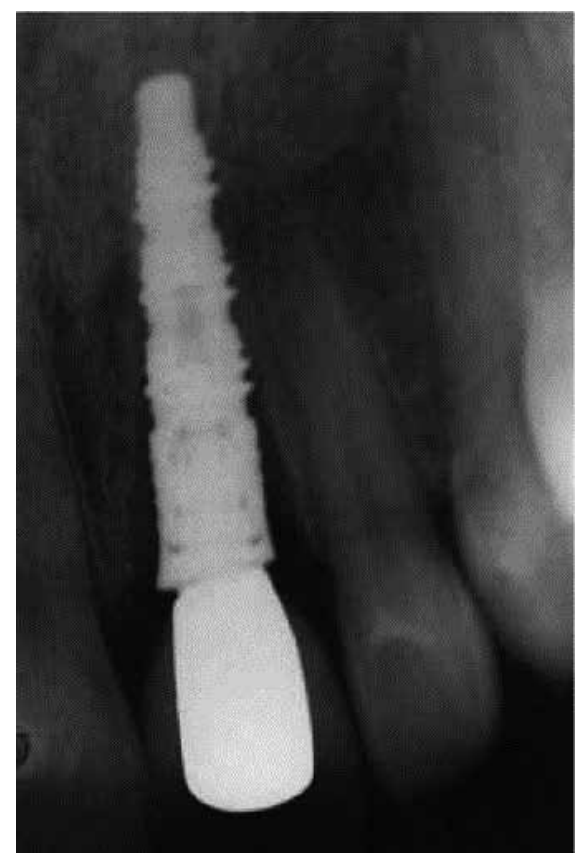

Fig. 3. Radiography in 2 days after trauma

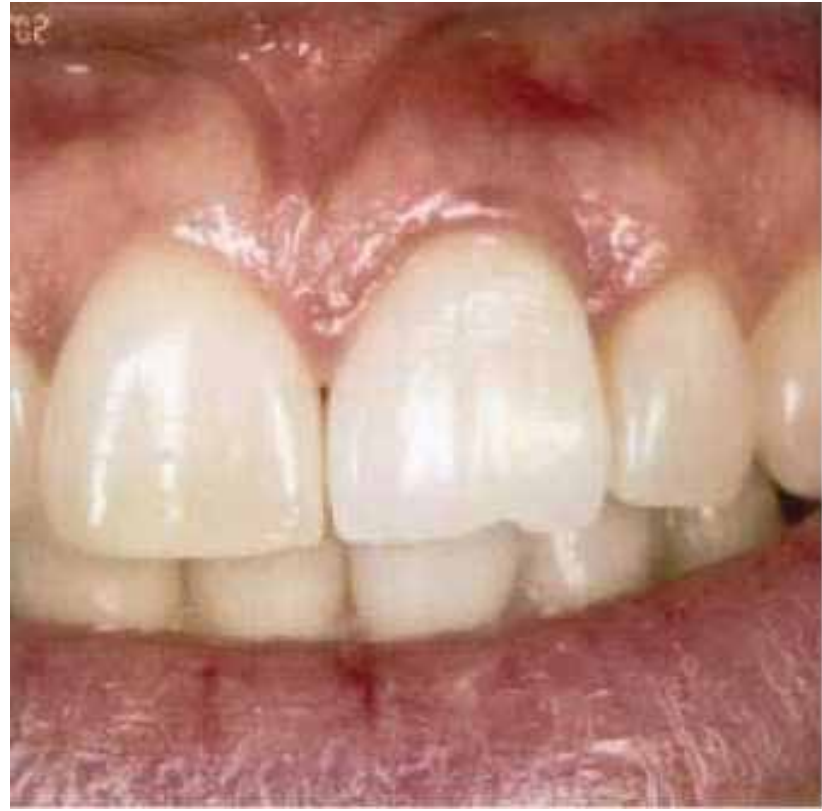

Fig. 2. Porcelain fracture and local gingivitis in 2 days after trauma

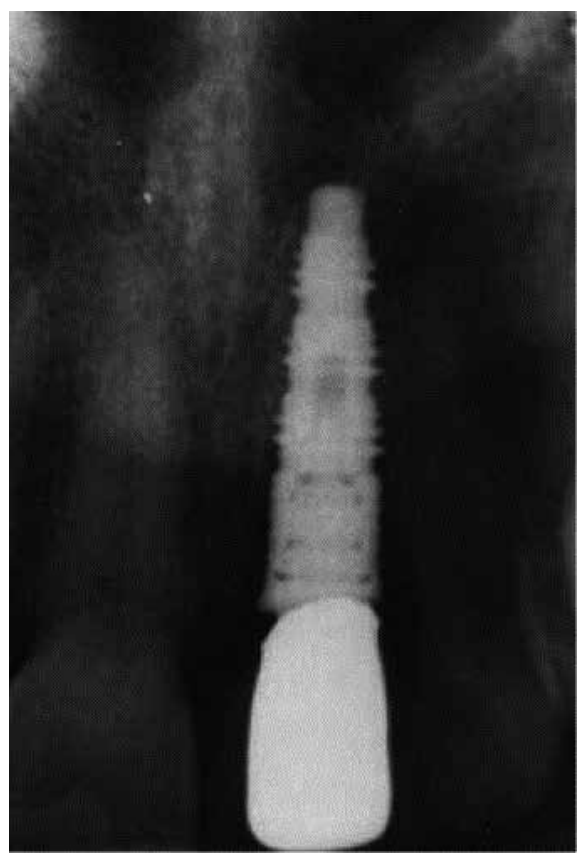

Fig. 4. Radiography in 5 months after trauma

\section{CASE REPORT}

A 25-year-old woman was indicated extraction of tooth 21. Endodontic and full crown treatments were failed; so, the tooth was not restorable. The tooth was extracted and intraosseous implant was immediately placed. A $1-\mathrm{mm}$ gap at the lingual surface was filled with a bioactive glass ceramic (Fig.1).

A provisional removable denture replacing 21 was adjusted, relieved over the implant site and delivered. In half of a year, an abutment was placed, torqued into place and restored with a cemented metal-ceramic crown. The patient was satisfied with the results of prosthetics. But in a week, the patient needed for emergency treatment with a complaint of a fractured 21 crown and implant displacement. In anamnesis, two days before her visit, she had occlusion trauma to the implant crown. Any pain was absent. Objectively: the crown was mobile; it had fracture of ceramic on the cutting edge. The crown was in its original position. The gingival margin was a little swelling and hyperaemic (Fig. 2).

The implant was removal and no longer integrated (Fig. 3). The patient was prescribed anti-inflammatory and antimicrobial treatment.

The crown was cut and removed from the abutment. The implant was found to be immobile, apparently still 
integrated and undamaged. The abutment retaining screw had apparently loosened from the occlusion trauma. They were removed, inspected, found to be undamaged and replaced to their original positions. The abutment screw was again seated with a torque wrench. A new crown was made and cemented.

The implant has not exhibited any adverse effects from the trauma and there has been no unusual bone loss or other problems (Fig. 4).

When trauma of natural tooth occurs, the bone is suddenly compressed against the conical root and the tooth is propelled occlusal breaking the supporting periodontal ligament. A dental implant has no periodontal ligament but can have threads and a rough surface that may preclude avulsion.

A tooth that is luxated may fully recover by temporarily splinting the injured tooth to its neighbours for support for healing. The treatment for a mobile implant is probably removal. A dis-osseointegrated implant may develop infection, fibrous encapsulation or epithelial down-growth.

Natural teeth that are fractured can be restored unless a root fracture necessitates extraction. Apparently from the case now presented, an integrated implant fixture can sustain some magnitude of external trauma and survive.

It is possible that the bone around an implant can be destroyed. It seems that component parts loosen or fracture before the implant or the integrated bone housing fractures. Component screw loosening and fracture can occur before bone loss around implant fixtures restored in occlusal disharmony.

Thus, occlusal forces are variable, frequent, and multidirectional and increase the risk of failure, if non-axial. These occlusal forces always produce stress at the neck of an implant [16]. Axial forces produce the lowest stress. So, cclusal prosthetic design should, at best, prevent or minimize exposure to non-axial forces [17].

The molecular basis of the toughness and strength of bone is largely unknown. Bone is a nanocomposite of hydroxyapatite crystals and a collagen matrix. The crystals of hydroxyapatite cannot dissipate much energy from an impact, so the collagen matrix remains as the probable energy-absorbing entity. These bonds are thought to be responsible for the toughness of bone [18].

Microfractures of bone around implants are associated with oblique loads, high occlusal stress magnitudes and an absence of cortical bone [19]. Bone microcracks are precursors to fracture. The way bone is structured helps prevent crack initiation in transverse fracture under tension, shear and tear [20]. It can be that an osseointegrated implant encased in adequate cortical bone could successfully survive a severe sudden traumatic impact of substantial force.

\section{CONCLUSIONS}

Dental implants are protected in cortical bone from traumatic occlusion impact. It is due to collagen, the matrix of bone, which helps to prevent bone from fracture. In our case, the occlusion forces were strong enough to ceramic fracture on crown and loosen the abutment retaining screw. The impact force caused no apparent damage to the bone, the implant or its components except abutment screw loosening. The force delivered at the incisal edge of the crown (axial direction) probably induced a reverse torque to the implant and did not result in its failure or bone resorption.

\section{REFERENCES}

1. Sugiura T., Yamamoto .K, Horita S., Murakami K. et al. Effects of implant tilting and the loading direction on the displacement and micromotion of immediately loaded implants: an in vitro experiment and finite element analysis. Journal of Periodontal and Implant Sciences. 2017; 47(4): 251-262.

2. Guglielmotti M., Olmedo D., Cabrini R. Research on implants and osseointegration. Periodontology 2000. 2019; 79(1): 178-189.

3. Woods B., Schenberg M., Chandu A. A comparison of immediate and delayed dental implant placement in head and neck surgery patients. Journal of Oral Maxillofacial Surgery. 2019. doi: 10.1016/j. joms.2019.02.007.

4. Salvi G., Monje A., Tomasi C. Long-term biological complications of dental implants placed either in pristine or in augmented sites: A systematic review and meta-analysis. Clinical Oral Implants Research. 2018; 16: 294-310.

5. Cicciù M., Cervino G., Milone D., Risitano G. FEM investigation of the stress distribution over mandibular bone due to screwed overdenture positioned on dental implants. Materials (Basel). 2018; 11(9):1512.

6. Drago C., Howell K. Concepts for designing and fabricating metal implant frameworks for hybrid implant prostheses. Journal of Prosthodontics. 2012; 21(5): 413-424.

7. Drew H., AlnassarT., GluckK., Rynar J. Considerations for a staged approach in implant dentistry. Quintessence International. 2012; 43(1): 29-36.

8. Chatterjee S., Sarkar S., Kalidindi S., Basu B. Periprosthetic biomechanical response towards dental implants, with functional gradation, for single/ multiple dental loss. Journal of Mechanical Behavior of Biomedical Materials. 2019; 94: 249-258.

9. Vahey B., Sordi M., Stanley K. et al. Mechanical integrity of cement- and screw-retained zirconium-lithium silicate glass-ceramic crowns to Morse taper implants. Journal of Prosthetic Dentistry. 2018; 120 (5): 721-731.

10. Gottlow J., Dard M., Kjellson F., Obrecht M. et al. Evaluation of a new titanium-zirconium dental implant: a biomechanical and histological comparative study in the mini pig. Clinical Implant Dentistry and Related Research. 2012; 14 (4): 538-545.

11. Cooper L.F., Reside G., Stanford C. et al. Three-year prospective randomized comparative assessment of anterior maxillary single implants with different abutment interfaces. International Journal of Oral Maxillofacial Implants. 2019; 34 (1): 150-158.

12. Crespi R., Fabris G., Crespi G. et al. Effects of different loading protocols on the bone remodeling volume of immediate maxillary single implants: a 2- to 3-year follow-up. Int Journal of Oral Maxillofacial Implants. 2019. doi: 10.11607/jomi.6972.

13. Chen Z., Li J., Wang H.L., Yu H. Initial bone volume changes after immediate implant placement associated with filling the gap using bovine bone in molar sites. International Journal of Oral Maxillofacial Implants. 2019; 34 (2): 521-528.

14. Sanda M., Fueki K., Bari P.R., Baba K. Comparison of immediate and conventional loading protocols with respect to marginal bone loss around implants supporting mandibular overdentures: A systematic review and meta-analysis. Japanese Dental Science Review. 2019; 55(1): 20-25. 
15. Kern J.S., Kern T., Wolfart S., Heussen N. A systematic review and meta-analysis of removable and fixed implant-supported prostheses in edentulous jaws: post-loading implant loss. Clinical Oral Implants Research. 2016; 27(2): 174-195.

16. Da Silva J.D., Kazimiroff J., Papas A. et al. Outcomes of implants and restorations placed in general dental practices: a retrospective study by the practitioners engaged in applied research and learning (PEARL) network. Journal of American Dental Association. 2014; 145(7): 704-713.

17. Uto Y., Kuroshima S., Nakano T. et al. Effects of mechanical repetitive load on bone quality around implants in rat maxillae. PLoS One. 2017; 12 (12): doi:10.1371/journal.pone.0189893

18. Perez J.R., Kouroupis D., Li D.J., Best T.M. et al. Tissue engineering and cell-Based therapies for fractures and bone defects. Frontiers in Bioengineering and Biotechnology. 2018; 6: 105.

19. Granke M., Makowski A.J., Uppuganti S., Does M.D. et al. Identifying novel clinical surrogates to assess human bone fracture toughness. Journal of Bone Mineral Research. 2015; 30 (7): 1290-1300.

20. Wusiman P., Taxifulati D., Weidong L., Moming A. Three-dimensional versus standard miniplate, lag screws versus miniplates, locking plate versus non-locking miniplates: Management of mandibular fractures, a systematic review and meta-analysis. Journal of Dental Sciences. 2019; 14(1): 66-80.
Self-financing research work of the department of prosthetic dentistry of State Institution "Dnipropetrovs'k Medical Academy of the Ministry of Health of Ukraine" (Dnipro, Ukraine) "Development and improvement of prosthetic methods in the complex treatment of stomatological diseases".

\section{ORCID and contributionship:}

Olena O. Fastovets: 0000-0002-2769-3244 ${ }^{\text {A,C,F }}$

Roman A. Kotelevskyi: 0000-0003-1140-2542 ${ }^{D, E}$

Yurii S. Huriev: 0000-0003-2677-6694 ${ }^{B}$

Serhii S. Kobyliak: 0000-0001-9117-0723 ${ }^{B}$

\section{Conflict of interest:}

The Authors declare no conflict of interest.

\section{CORRESPONDING AUTHOR \\ Olena 0. Fastovets}

State Institution "Dnipropetrovs'k Medical Academy of the Ministry of Health of Ukraine"

9 Vernadsky St., 49044 Dnipro, Ukraine

tel:+380979921124

e-mail: fastovets.e@ex.ua

Received: 04.03 .2020

Accepted: 05.11 .2020

A - Work concept and design, B - Data collection and analysis, C - Responsibility for statistical analysis,

D-Writing the article, $\mathbf{E}$-Critical review, $\mathbf{F}$ - Final approval of the article 